\title{
Economia ambiental, ecológica e valoração dos serviços ambientais: uma revisão mais que necessária
}

\author{
Pedro Luiz Teixeira de Camargo' \\ Arnaldo Freitas de Oliveira Júnior ${ }^{2}$ \\ Paulo Pereira Martins Junior
}

\begin{abstract}
Resumo: Estudos capazes de explicar, mesmo que de forma resumida, o surgimento histórico das correntes teóricas que dialogam com o meio ambiente dentro das Ciências Econômicas, assim como as principais técnicas de valoração dos serviços ambientais sempre são importantes, principalmente no momento atual em que essa temática está nas manchetes de jornais e revistas. Pensando nisso, propôs-se esse artigo, que objetiva caracterizar e explanar, de maneira didática, o surgimento das duas principais áreas das Ciências Econômicas que estudam as relações com a natureza sob um viés conservacionista: a Economia Ecológica e a Economia Ambiental. A metodologia escolhida foi o estudo teórico e bibliográfico. Como resultado, além da explanação histórica de ambas, foram apresentados os métodos e técnicas de cálculo das externalidades da natureza, as chamadas metodologias de valoração ambiental, com destaque para as mais popularmente utilizadas: Método do Custo de Viagem; Método dos Preços Hedônicos; Valor de Propriedade (com maior ênfase para a Metodologia de Costanza et al. (1997); Disposição a Aceitar pela Perda de Funções Ambientais e o Método de Avaliação Contingencial (MAC). Como conclusão, é possível afirmar que trabalhos teóricos de valoração ambiental são ainda recentes na área acadêmica. Tendo em vista o seu baixo custo de aplicação prática e a capacidade de produzir resultados aceitáveis, essas técnicas podem apresentar vantagens monetárias significativas em relação a outras metodologias. Portanto, popularizar seu uso como ferramenta científica confiável pode ser uma importante contribuição para a conservação da natureza.
\end{abstract}

Palavras-chave: Economia ecológica e ambiental. Métodos e técnicas de valoração. Revisão bibliográfica. Serviços ecossistêmicos.

Abstract: Studies capable of explaining, even in a summarized way, the historical emergence of the theoretical currents that dialogue with the environment within the Economic Sciences as well as the main techniques of valuation of environmental services is always important, even more at the present moment where this theme is in the headlines of newspapers and magazines. On this basis, this article was proposed, whose chosen methodology was the theoretical and bibliographic study, which aims to characterize and explain, in didactic way, the emergence of the two main areas of Economic Sciences that study relations with nature under a conservationist bias: the Ecological Economy and the Environmental Economy. As a result, besides the historical explanation of both, the methods and techniques for calculating the externalities of nature, the so-called environmental valuation methodologies, were also presented, especially the most popular ones: Cost of Travel Method; Hedonic Price Method; Property Value (with greater emphasis on the Methodology of Costanza et al. (1997); Disposition to Accept for the Loss of Environmental Functions and the Contingency Assessment Method (CAM). In conclusion, it can be affirmed that theoretical studies of environmental valuation are still recent in the academic area. Given their low cost of practical application and the ability to produce acceptable results, these

\footnotetext{
${ }^{1}$ Doutorando do Programa de Pós-graduação em Evolução Crustal e Recursos Naturais da Universidade Federal de Ouro Preto (UFOP), Departamento de Geologia. Professor Formador de Economia Ambiental do curso técnico em Controle Ambiental do Instituto Federal de Minas Gerais Campus Ouro Preto (CEAD-IFMG). E-mail: pedro0peixe@yahoo.com.br. ${ }^{2}$ Doutor em Ecologia pela UNESP e Professor Efetivo do curso de Gestão da Qualidade do Instituto Federal de Minas Gerais, Campus Ouro Preto (IFMG).

${ }_{3}^{3}$ Doutor em Geologia pela Universidade de Paris e Professor Adjunto IV do curso de Geologia da Escola de Minas, Departamento de Geologia da UFOP.
}

Página 69 Caderno de Ciências Sociais Aplicadas, Vitória da Conquista/BA, vol. 15, n² 26, ano 15, p. 69-89, jul/dez 2018. 
techniques may have significant monetary advantages over other methodologies. Therefore, popularizing its use as a reliable scientific methodology can be an important contribution to the conservation of nature.

Keywords: Bibliographic review. Ecological and environmental economics. Ecosystem services. Methods and valuation techniques.

\section{Introdução}

Desde que o debate acerca da sustentabilidade se tornou um dos principais temas do século XXI, a busca pela preservação e valorização dos recursos naturais tem sido cada vez mais comum. Entretanto, cabe perguntar, quando de fato começou a preocupação mundial com a conservação da natureza?

Segundo Gonçalves-Dias et al. (2007), a participação da Organização das Nações Unidas (ONU) nesse tema se inicia na Conferência de Estocolmo, em 1972, quando se criou o United Nations Environment Program (UNEP).

Outros marcos no debate ambiental, fruto das Conferências de Meio Ambiente da ONU (Tabela 1), são o Relatório Brundtland, organizado pela Comissão Mundial sobre Meio Ambiente e Desenvolvimento da ONU (1987), em que se apresentou o significado definitivo de "Desenvolvimento Sustentável "," e a Conferência das Nações Unidas sobre Meio Ambiente de 1992 (ECO 92), que colocou a espécie humana como o principal foco do desenvolvimento sustentável, garantindo-se a esses indivíduos uma vida saudável, produtiva e harmônica em relação à natureza.

Tabela 1 - Principais acontecimentos nas Conferências de Meio Ambiente.

\begin{tabular}{|c|c|c|}
\hline \multicolumn{3}{|c|}{ Conferências Mundiais de Meio Ambiente } \\
\hline Nome & Destaque & Local e ano \\
\hline Conferência de Estocolmo & Criação do UNEP & Suécia, 1972 \\
\hline Conferência de Toronto & Criação do IPCC e divulgação do Relatório Brundtland & Canadá, 1988 \\
\hline Conferência de Genebra & $\begin{array}{l}\text { IPCC mostra sinais de aumento da temperatura do } \\
\text { planeta }\end{array}$ & Suíça, 1990 \\
\hline Conferência do Rio de Janeiro & $\begin{array}{c}\text { Criação da agenda } 21 \text { e da Convenção da } \\
\text { Biodiversidade }\end{array}$ & Brasil, 1992 \\
\hline Conferência de Berlim & $1^{a}$ Conferência das Partes (COP-1) & Alemanha, 1995 \\
\hline
\end{tabular}

\footnotetext{
${ }^{4}$ Segundo a Comissão Mundial sobre Meio Ambiente e Desenvolvimento da ONU (1987), "Desenvolvimento Sustentável" é o modelo econômico capaz de atender às necessidades do presente sem comprometer a capacidade das gerações futuras de atenderem as suas próprias necessidades.
}

Página 70 Caderno de Ciências Sociais Aplicadas, Vitória da Conquista/BA, vol. 15, nº 26, ano 15, p. 69-89, jul/dez 2018. 


\section{- CAdERNOS de CIENNCIAS SOCIAIS ApLICADAS}

Conferência de Genebra

Conferência de Kyoto

Conferência em Buenos Aires

Conferência de Bonn

Conferência de Haia

Conferência de Marrakesh

Conferência de Nova Delhi

Conferência de Milão

Conferência de Buenos Aires

Conferência de Montreal

Conferência de Nairóbi

Conferência de Bali

Conferência de Poznan

Conferência de Copenhague

Conferência em Cancún

Conferência em Durban

Rio +20
Países em desenvolvimento receberiam apoio financeiro para redução de gases

Protocolo de Kyoto (Sem EUA), redução de gases estufa, certificados de carbono

Plano de Ação de Buenos Aires

Reuniões sobre a Mudança de Uso da Terra e Florestas

Aumento dos conflitos entre EUA (não assina termo) e União Europeia

Efeito estufa e atividades humanas

Mecanismo de Desenvolvimento Limpo

Regulamentação de projetos de reflorestamento para créditos de carbono

Novas metas do Protocolo de Kyoto após 2012

Brasil propõe duas formas de negociação pra redução de gases

Relatório Stern (Inglaterra) e Redd (Brasil)

Fundo de Adaptação e Namas

BRICS se comprometem a reduzir gases

Acordo de Copenhague

Fundo Verde do Clima

Nova etapa para o Protocolo de Kyoto (2017)

Renovar o compromisso para o desenvolvimento
Suíça, 1996

Japão, 1997

Argentina, 1998

Alemanha, 1999

Holanda, 2000

Marrocos, 2001

Índia, 2002

Itália, 2003

Argentina, 2004

Canadá, 2005

Quênia, 2006

Indonésia, 2007

Polônia, 2008

Dinamarca, 2009

México, 2010

África do Sul, 2011

Brasil, 2012

sustentável

Para Soares et al. (2004), a partir desses eventos foi possível, definitivamente, introduzir a compreensão de que os bens naturais são finitos e de que é importante pensar formas reais de conscientização e de conservação dos ativos naturais.

Prova disso é que entre as resoluções da ECO 92 está a mensuração do desenvolvimento sustentável. Entretanto, cabe aqui uma pergunta chave: como calcular esse valor relacionando-o com um determinado ambiente natural?

Para Mueller (1998, p.71):

“(...) a matéria e a energia usados pelo sistema econômico não surgem do nada e nem desaparecem com o uso nos processos de produção e de consumo; são captadas do meio ambiente e acabam sendo restituídas a ele nas mesmas quantidades iniciais, embora qualitativamente alteradas".

Dessa forma, ao analisar economicamente determinada região, é possível verificar "de onde vem e para onde vão" a matéria e a energia de um ativo ambiental. Para tanto, é necessário compreender que

Página 71 Caderno de Ciências Sociais Aplicadas, Vitória da Conquista/BA, vol. 15, n 26, ano 15, p. 69-89, jul/dez 2018. 
esse bem é um recurso natural finito (escasso), portanto, os efeitos exteriores que ele possa vir a sofrer precisam ser tratados assim, ou seja, como internalidades do sistema.

Com base no preceito de que é possível internalizar monetariamente as externalidades (DENARDIN, 2002), realizou-se o estudo aqui descrito, cujo objetivo é caracterizar e explicar, de maneira didática, o surgimento das duas principais áreas das Ciências Econômicas que estudam as relações com a natureza sob um viés conservacionista: a Economia Ecológica e a Economia Ambiental (e também a Economia dos Recursos Naturais, corrente minoritária que deu origem as outras duas). Tanto na Economia Ecológica quanto na Economia Ambiental destacam-se os métodos e técnicas de cálculo das externalidades na natureza, as metodologias de valoração ambiental.

\section{Metodologia}

Tendo em vista ser este um artigo teórico, a metodologia de pesquisa pautou-se em levantamento bibliográfico acerca do tema, fichamento, leitura e análise de trabalhos e seus resultados acerca dessa temática.

\section{Resultados e discussões}

Economia dos recursos naturais: seu início e diferenças entre economia ambiental e economia ecológica

Mattos et al. (2004) declaram que a Economia é uma ciência em constante desenvolvimento. Quando se observa a sua relação com temáticas relacionadas ao meio ambiente, é possível dividi-la em duas vertentes: a Economia Ambiental e a Economia Ecológica. Entretanto, ambas são originárias da primária Economia de Recursos Naturais.

Essa corrente primária, vigente no início da década de 1960, seria aquela que se preocupava sobremaneira com "como" e "por que" se utilizar os recursos naturais. Pelo fato de objetivar o uso ótimo dos recursos naturais, não conseguiu evitar, de fato, a degradação do meio ambiente.

Nessa corrente, o mais importante evento foi o lançamento do livro Primavera Silenciosa (Silent Spring) de Rachel L. Carson, em 1962. Esse livro, que trata, entre outros temas, dos efeitos do diclorodifenil-tricloroetano (DDT) em trabalhadores rurais ingleses, influenciou a rede de televisão britânica

Página 72 Caderno de Ciências Sociais Aplicadas, Vitória da Conquista/BA, vol. 15, n 26, ano 15, p. 69-89, jul/dez 2018. 
CBS a realizar um documentário sobre as consequências desse agrotóxico no organismo humano. $\mathrm{Na}$ ocasião, o filme foi assistido por mais de 15 milhões de espectadores.

Apesar de essa obra ser considerada um ícone do jornalismo, não é correto afirmar que foi a partir dela que a preocupação com a preservação da natureza efetivamente começou. Também não é correto deduzir que a Economia de Recursos Naturais traria respostas para os então crescentes questionamentos acerca da conservação dos ativos naturais. Como salienta McCormick (1992, p. 21), "não houve um acontecimento claro que inflamasse um movimento de massas, nenhum grande orador ou profeta que surgisse para incendiá-las”. Portanto, apesar de suas contribuições Carson e seus seguidores não conseguiram, na prática, criar um fato político (ou evento acadêmico) capaz de representar uma ruptura com a então (e pouco efetiva) lógica economicista.

Assim, pelo fato de a Economia de Recursos Naturais não apresentar propostas plausíveis para resolver as demandas ambientais crescentes, surgiu, nos Estados Unidos, a Economia Ambiental. Essa corrente nasceu como resposta às pressões relativas às regulamentações de bens naturais na segunda metade da década de 1960, uma clara resposta para a piora da qualidade de vida da população estadunidense por conta do aumento desenfreado dos poluentes presentes na água e no ar (PEARCE e WARFORD, 1993).

Como qualquer subparte das Ciências Econômicas, a Economia Ambiental pode ser melhor entendida se observada à luz da lei da conservação da matéria. Tendo em vista o que postula essa lei "nada se cria nem se destrói”, não se concebe uma situação em que algo possa obter ganhos sem o outro ter perdas. Isso acontece, "pois, o processo econômico, se não for induzido a nenhuma mudança quantitativa, nem sofrer mudanças qualitativas de onde está imerso, se torna um sistema isolado, autocontido e histórico" (GEORGESCU-ROEGEN, 1971 p. 2).

Os primórdios da Economia Ambiental constituíam a necessidade de se controlar o uso desenfreado das diferentes estruturas naturais. O destaque era para os problemas de poluição que começaram a aparecer nas metrópoles dos países mais desenvolvidos, como os EUA (PEARCE e WARFORD, 1993), por exemplo, e a crise do petróleo, que resultou em um aumento desenfreado do preço desse produto no mercado mundial na década de 1970 (CROOPER e OATES, 1992).

Para responder a esses graves problemas, em 1983, as Nações Unidas instituíram a Comissão Mundial do Meio Ambiente e Desenvolvimento (CMMD), com o objetivo de sugerir meios para a resolução das questões oriundas do excesso de poluentes presentes no processo de manufatura das grandes indústrias.

Página 73 Caderno de Ciências Sociais Aplicadas, Vitória da Conquista/BA, vol. 15, n 26, ano 15, p. 69-89, jul/dez 2018. 
Entretanto, essa comissão não se mostrou totalmente eficiente. Os problemas percebidos ao longo das décadas de 1960 e 1970 (em especial) seguiram praticamente da mesma forma. Para Merico (1996), essa vertente de pensamento (Economia Ambiental), assim como a anterior (Economia de Recursos Naturais), não discutia de maneira correta a relação dicotômica entre os ecossistemas e a biosfera, o que, na prática, originou a terceira (e mais recente) das correntes econômico-ambientais: a Economia Ecológica.

$\mathrm{Na}$ verdade, a Economia Ecológica surgiu na academia um pouco antes da Economia Ambiental. Durante a segunda metade da década de 1960 e início dos anos 1970, o debate acerca da conservação da natureza estava na ordem do dia, devido ao surgimento do chamado Clube de Roma em $1968^{5}$ e também à publicação de alguns trabalhos que se tornariam clássicos dentro dessa vertente. São exemplos: "The Economics of the Coming Spaceship Earth" (1966) de Kenneth Boulding, "The Entropy Law and the Economic Process" (1971), de Nicholas Georgescu-Roegen, "On Economics as a Life Science" (1968) de Herman Daly e "Environment, Power and Society" (1971), de Howard Odum.

Apesar de seus primórdios, a Economia Ecológica consolida-se, de fato, muito tempo depois da Economia Ambiental, exatamente com a fundação da International Society for Ecological Economics (ISEE), em 1988, e com a criação da revista Ecological Economics em 1989. O fracasso da conservação ambiental dentro do modelo econômico neoliberal, liderado por Reagan (EUA) e Tatcher (Inglaterra), na década de 1980, ajuda a explicar a ascensão dessa nova vertente nesse período histórico, já que, no campo político, ela representava um rompimento com a visão liberal dos ativos naturais.

No campo científico, essa terceira corrente se baseava (e se baseia) em dois pilares fundamentais: 1) o fato de que um sistema econômico deve ser considerado na sua mais ampla escala, seja ela temporal ou mesmo espacial; 2) as condições físicas e químicas irão influenciar sobremaneira todo esse sistema, uma vez que é de lá que se derivam a energia e a matéria-prima a serem utilizadas.

Resumindo, como a termodinâmica é uma lei em completa evolução, para os economistas ecológicos significa dizer que a Economia deveria passar a ser observada dentro do campo multidisciplinar, uma vez que as decisões econômicas impactarão sobre o crescimento social, ou seja, o “problema ambiental está na forma de desenvolvimento da sociedade" (GEORGESCU-ROEGEN, 1971, p. 12).

\footnotetext{
${ }^{5}$ Reunião realizada por cientistas, industriais e políticos na capital da Itália, objetivava discutir e analisar os limites do crescimento econômico de acordo com o crescente uso dos recursos naturais. Seu relatório final serviu de inspiração para muitos dos debates ocorridos em 1972, na Conferência das Nações Unidas sobre o Ambiente Humano, conhecida como Conferência de Estocolmo.
}

Página 74 Caderno de Ciências Sociais Aplicadas, Vitória da Conquista/BA, vol. 15, n² 26, ano 15, p. 69-89, jul/dez 2018. 


\section{Métodos e técnicas de valoração econômica ambiental}

Após um breve diálogo sobre a história das correntes econômicas relacionadas ao meio ambiente no campo teórico, cabe comentar um pouco sobre os métodos e técnicas de mensuração ambiental.

Os tipos de metodologia de cálculo sempre são um dos temas mais debatidos dentro da Economia Ecológica e Ambiental. Parte disso ocorre pelo fato de se tentar buscar uma maneira única que seja capaz de conciliar as diversas técnicas existentes, facilitando seu uso e popularização (CAVALCANTI, 1995).

Entretanto, essa junção não é fácil e um dos motivos que impedem essa unificação de metodologias é o fato de que ecossistemas diferentes possuem condições específicas diferentes, ou seja, não se pode definir o indefinível. O ideal é que se escolha o melhor método relacionado àquele determinado bem ambiental (OLIVEIRA JUNIOR, 2003) e, se possível, realizar o maior número de tentativas e métodos até ser possível concluir qual o mais adequado a cada ambiente natural (MERICO, 1996).

Com base nessa premissa, tem sido comum, portanto, o uso de diferentes técnicas de valoração econômica dos recursos naturais. Algumas dessas metodologias, inclusive, relacionam-se ao uso e ao não uso desses recursos. Além dessas técnicas, Nogueira e Medeiros (1999) vão além e defendem o uso de razões não econômicas que possam vir a ter consequências parcimoniosas significativas. Esses e outros procedimentos serão observados na próxima seção, que tratará especificamente das principais metodologias possíveis de ser usadas para valorar determinado bem ambiental.

\section{Valor econômico total}

O termo valor econômico total pode ser entendido como a soma dos valores de uso e não uso de certo local (ORTIZ, 2003). Esse valor de uso seria a soma dos Valores Diretos de Uso (VUD) da área e Indireto (VUI).

Para um melhor entendimento dessas definições, pode-se tomar como exemplo de usos diretos de um bem ambiental a caça e a coleta realizadas no local, enquanto o uso indireto pode ser observado percebendo-se a qualidade da água e a beleza natural ali presentes (ORTIZ, 2003).

Página 75 Caderno de Ciências Sociais Aplicadas, Vitória da Conquista/BA, vol. 15, n² 26, ano 15, p. 69-89, jul/dez 2018. 
Outro autor, Mota, em 2001, para melhor explanar essa relação, propôs o uso de uma equação econométrica (Equação I):

$$
(\text { VET })=\text { Valor de uso (VU) + valor de opção (VO) + valor de existência (VE) I }
$$

Nessa equação, VU deveria ser a soma do VUD e VUI. Com base nesse raciocínio, é possível compreender o VUD como o valor atribuído pelo indivíduo à utilização efetiva e atual de um bem ou serviço ambiental.

O VUI pode ser adjudicado como os benefícios oriundos da preservação desse recurso e o $\mathrm{VO}$, referindo-se à escolha de que se pode fazer em não usufruir o bem ou serviço ambiental no presente, de modo que este possa ser útil ou trazer benefícios futuros.

Por último tem-se o VE, entretanto este se refere à compreensão de que, independentemente do uso direto ou indireto, presente ou futuro, a preservação dos recursos naturais deve prevalecer pelo simples fato de existir. O VE tem relação com valores morais, éticos e altruísticos, deixando, portanto, sua valoração como o bem mais complexo de ser entendido.

Para melhor compreender essa relação, é interessante observar a Figura 1: 


\section{- Cadernos de CiêncIas SOCIAIS APLICADAS}

Figura 1 - Explanação didática de valores referentes ao Valor Econômico Total (VET).

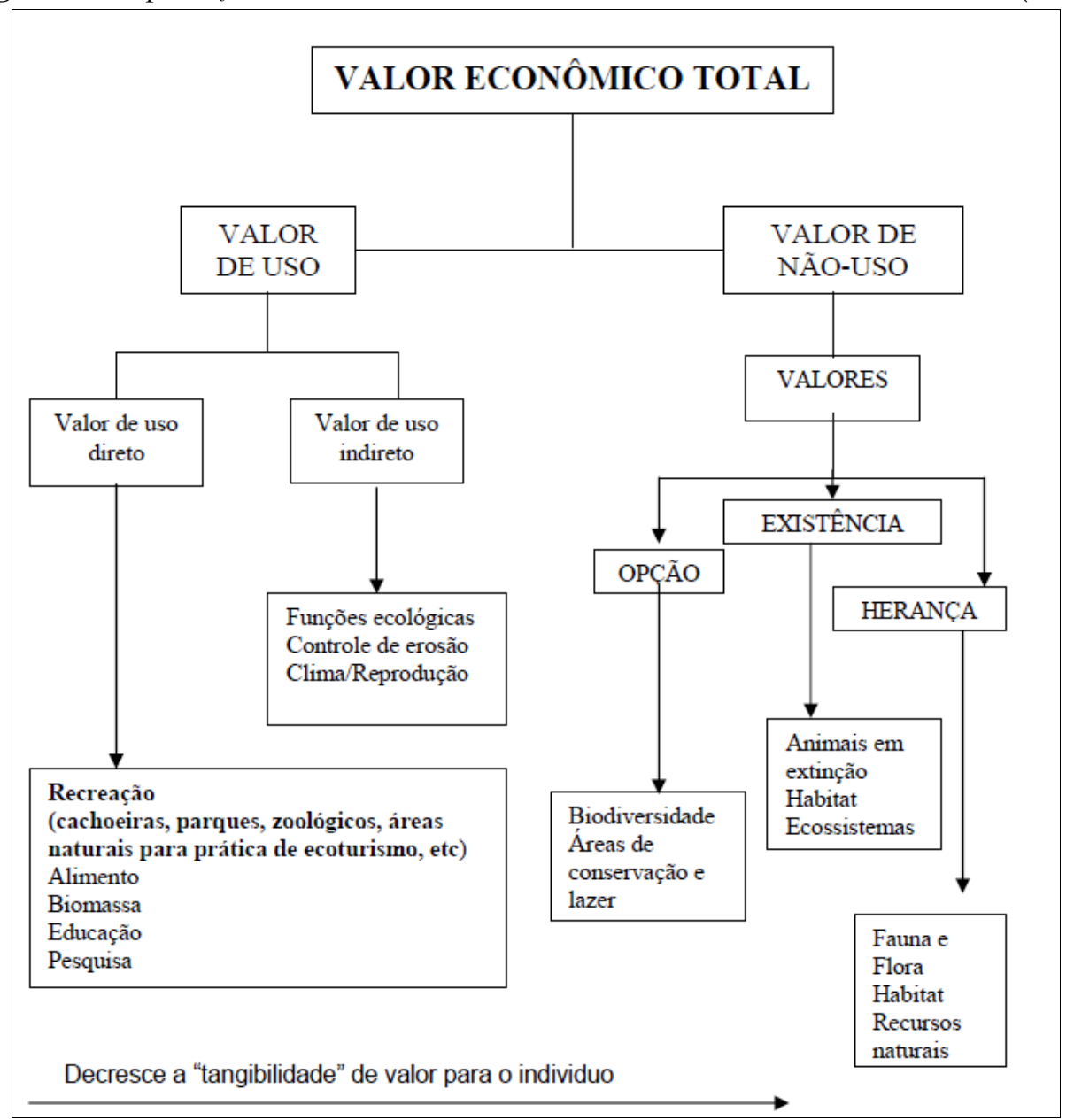

Fonte: Oliveira Junior (2003, p.57).

Ao grafar a Figura 1, Oliveira Júnior (2003) vai além da fórmula apresentada por Mota (2001), abarcando outros fatores e colocando-os de maneira didática, facilitando a compreensão do VET.

Um desses fatores foi o Valor de Uso Indireto (VUI), que possui relação com as funções ecológicas ecossistêmicas, tendo em vista seu papel para a plena biodiversidade local (MOTA, 2001). Nessa opção, é possível colocar todos os benefícios oriundos do que a área natural pode contribuir em termos de produção e uso (OLIVEIRA JUNIOR, 2003). Exemplos disso são o controle de erosão e a manutenção da qualidade da água (OBARA, 1999).

O último dos fatores apresentados é o valor de não uso (VNU). Oliveira Junior (2003) mostra que para a obtenção do VNU, o ideal é somar outros três valores: Opção, Existência e Herança.

- Valor de Opção (VO): essa importância será aquela que o indivíduo aceita pagar para ter o uso futuro desse bem (BELLIA, 1996).

Página 77 Caderno de Ciências Sociais Aplicadas, Vitória da Conquista/BA, vol. 15, nº 26, ano 15, p. 69-89, jul/dez 2018. 
- Valor de Existência (VE): essa opção denota o valor que pode ser dado a um recurso, independentemente de seu uso (BELLIA, 1996). Oliveira Junior (2003) ultrapassa essa definição e coloca uma situação interessante: o fato de muitas pessoas defenderem a preservação de um determinado local ou bem natural sem ao menos conhecê-lo, mostrando um exemplo prático dessa opção de valoração.

- Valor de Herança (VH): seria o valor que o cidadão está disposto a desembolsar de maneira que as futuras gerações tenham condição de fazer uso de bens ambientais (OBARA, 1999). Cabe destacar que, apesar de parecidos, VO e VH são diferentes, o primeiro destina-se ao uso do próprio indivíduo no futuro; o segundo representa o que será utilizado por seus herdeiros genéticos.

\section{Metodologias diretas de valoração econômica ambiental}

Para caracterizar os principais métodos diretos de valoração, baseou-se em Mota (1997) ${ }^{6}$ :

a- Método do custo de viagem

Baseando-se nos gastos que o visitante precisa ter para fazer o uso recreativo de um bem natural, é possível estimar o valor que o turista tende a gastar durante todo o tempo do passeio, incluindo estadia, alimentação e transporte. Para tal, o valor agregado ao período de diversão é calculado ao gerar uma curva de demanda com base no ativo recreativo presente no local. Econometricamente, tem-se a Equação II:

\section{$\mathrm{V}=\mathrm{f}(\mathrm{CV}, \mathrm{X} 1, \mathrm{X} 2, \ldots, \mathrm{XN}) \quad$ II}

Sendo: V: Taxa de visitação do turista; CV: Custo médio da viagem por parte do turista; e X: Variável socioeconômica do entrevistado.

Há de se lembrar que aqui existe uma curva f de demanda em relação ao bem natural. Logo, se houver variação de $f$, uma vez que $f$ representa o número de turistas presentes no local (taxa de visitação), deduz-se que acontecerá uma alteração no custo de viagem a ser calculado.

Essa metodologia apresenta algumas vantagens, como a possibilidade de se valorar de forma direta e indireta um bem natural. Entretanto, não se consegue a obtenção de valores oriundos de

\footnotetext{
${ }^{6}$ Para mais informações: Manual para valoração econômica de recursos ambientais. IPEA/MMA/PNUD/CNPq Rio de Janeiro, 1997. Elaborado por Ronaldo Serôa da Motta, Coordenador de Estudos do Meio Ambiente do IPEA e Professor da Universidade Santa Úrsula.
}

Página 78 Caderno de Ciências Sociais Aplicadas, Vitória da Conquista/BA, vol. 15, no 26, ano 15, p. 69-89, jul/dez 2018. 
turistas não presentes no local de visita, tendo a desvantagem de ter no campo amostral somente os visitantes do perímetro turístico visitado. Um bom exemplo do uso dessa técnica é o trabalho de Barcelos, em 2014, realizando esse cálculo no Santuário do Caraça (MG).

b- Método dos preços hedônicos:

Com essa técnica, o objetivo é valorar o preço de um bem (ambiental inclusive) com base em valores do mercado financeiro. Um exemplo é o valor de determinado apartamento no comércio imobiliário. O valor desse imóvel pode sofrer diversas influências, a depender da sua localização, pois os poluentes do ar (em um grande centro) ou mesmo os ruídos de um avião, no caso de o imóvel situar-se próximo a um aeroporto, influenciam diretamente no valor final a ser pago por esse bem.

A função relacionada ao preço hedônico será aparece na equação III:

\section{$\mathrm{Pi}=\mathrm{f}(\mathrm{Si}, \mathrm{Ni}, \mathrm{Qi}) \quad$ III}

Sendo: Pi: preço do bem i; Si: características do bem i; Ni: características do entorno; e Qi: qualidade ambiental do bem i.

Atualmente, esse modelo tem sido muito utilizado na indústria de imóveis para determinação de valores relacionados à presença de poluentes. Vale ainda pontuar que essa metodologia consegue realizar a valoração de uso direto e indireto em diferentes locais, podendo também ser denominado “Mercado de Recorrência" (PEARCE e WARFORD, 1993, p. 138).

c- Valor de propriedade

Esse método consiste em relatar de que maneira determinada propriedade pode ou não ser influenciada pela qualidade de um ativo natural (DE GROOT, 1992). Podem ser calculados aqui, por exemplo, a qualidade da água e do ar. A mensuração de fatores como esses dos exemplos, inclusive, pode influenciar no preço final de uma determinada localidade, fazendo crescer (ou não) o seu valor dentro do mercado financeiro. Ou seja: o proprietário paga para por uma área, somando-se a esta os benefícios naturais ali presentes (OLIVEIRA JUNIOR, 2003). Nesse tópico entra a Metodologia de Costanza, et al. (1997), que será abordada com mais ênfase na próxima subseção.

d- Metodologia de Costanza et al. (1997)

$\mathrm{Na}$ realidade, essa metodologia faz parte daquelas denominadas "Valor da Propriedade" e propõe a valoração dos ecossistemas, reconhecendo nestes um valor hipotético de mercado.

De forma geral, os trabalhos com essa técnica, utilizam a tabela proposta por Costanza et al. (1997). O autor em questão é um economista ecológico da Universidade de Maryland, nos EUA, que, se utilizando do método de valoração contingente, estimou o valor dos 17 principais "serviços"

Página 79 Caderno de Ciências Sociais Aplicadas, Vitória da Conquista/BA, vol. 15, n 26, ano 15, p. 69-89, jul/dez 2018. 
oferecidos pelo meio ambiente (Tabela 2), tais como a oferta de oxigênio, captura de carbono, oferta de água, de produtos medicinais e alimentos, nos principais ecossistemas do planeta. Cabe destacar que, apesar de empírica, essa proposta é uma forma de se mensurar valores potenciais de serviços ecossistêmicos (COSTANZA et al., 1998).

Tabela 2 - Tabela de funções e serviços ecossistêmicos utilizados por Costanza (Adaptado de COSTANZA et

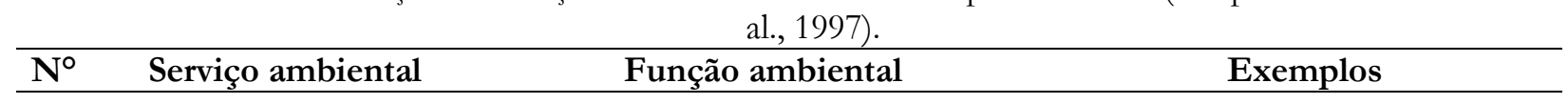

1 Regulação de gás

2 Regulação do clima

Regulação da temperatura e precipitação

3 Regulação de distúrbios

4 Regulação da água

5 Abastecimento de água

$6 \quad$ Controle de erosão

$7 \quad$ Formação do solo

$8 \quad$ Ciclo de nutrientes

9 Tratamento de resíduos atmosfera nutrientes
Regulação da composição química da

Balanço do $\mathrm{CO}_{2} / \mathrm{O}_{2}, \mathrm{O}_{3}$ para proteção contra raios UVB, e níveis de SOx.

Regulação dos gases do efeito estufa e produção de dimetilsulfeto (que afeta a formação de nuvens).

Proteção contra tormentas, controle de inundações, recuperação de secas e outros aspectos da resposta dos habitats à variabilidade ambiental, controlada

principalmente pela estrutura vegetal.

Oferta de água para usos agrícola (irrigação), industrial (fábricas) ou transporte.

Oferta de água por bacias hidrográficas, reservatórios e aquíferos.

Prevenção da perda do solo pelo vento, escorrimento superficial e outros processos de remoção; armazenamento de areia em lagos e áreas úmidas.

Decomposição de rochas e acumulação de matéria orgânica.

Fixação de nitrogênio, fósforo, potássio e outros elementos.

Recuperação de nutrientes celulares

Tratamento de resíduos, controle

Página 80 Caderno de Ciências Sociais Aplicadas, Vitória da Conquista/BA, vol. 15, nº 26, ano 15, p. 69-89, jul/dez 2018. 
11 Controle biológico

12

Produção de comida

14

Recreação

Cultura
Movimento de gametas florais

Regulação trófica de populações

Habitat para populações residentes e transitórias

Produção primária bruta extraída como alimento

\section{Produção primária bruta extraída} como matéria-prima

Fonte de matérias e produtos únicos

Oportunidade de recreação de poluição, detoxificação.

Suporte a polinizadores para a reprodução das populações de plantas.

Controle das espécies de presas por predadores-chave, redução da herbivoria por predadores do topo da cadeia.

Berçários, habitats para espécies migratórias e locais, habitats para espécies capturadas localmente ou durante os períodos de inverno.

Produção de pescado, caça, grãos, sementes e frutas através da pesca, caça, coleta e agricultura de subsistência.

Produção de madeira, lenha ou forragem.

Medicamentos, produtos para pesquisas em materiais, genes para resistência a patógenos de plantas e pestes de culturas. Entram ainda as espécies ornamentais.

Ecoturismo, pesca esportiva e outras atividades recreativas ao ar livre.

Valores estéticos, artísticos, educacionais, espirituais e/ou científicos dos ecossistemas.

O valor monetário global estimado para os recursos e serviços ambientais do planeta variou, segundo Costanza et al. (1997), na faixa de US\$ 06 - 54 trilhões/ano, o que resultou no valor médio de US\$ 33 trilhões/ano. Os banhados (ou terras úmidas) foram considerados os ecossistemas mais valiosos, fornecendo serviços ambientais estimados em US\$ 14.785,00/ha-ano. Para Costanza et al. (1998), os serviços ambientais do oceano apresentam um valor na casa de US\$252,00 e a floresta tropical US\$2.007/ano. Algo em torno de 63\% (US\$20,9 trilhões) do valor global dos recursos foi atribuído aos ecossistemas marinhos, sendo que a metade desse montante se refere às áreas costeiras. 
No grupo dos habitats terrestres, as florestas foram avaliadas em US\$ 4,7 trilhões, os banhados US $\$ 4,9$ trilhões, os ciclos de nutrientes valem US\$ 17 trilhões/ano, e serviços ambientais ao nível máximo foram valorados em US\$ 54 trilhões/ano (NETO, 2010).

A técnica de Valoração Ambiental apresentada por Costanza et al. (1997) perpassa pelo entendimento de que o capital natural é a função base do ecossistema local, função já identificada por outros autores, como Turner (1988) e De Groot $(1987 ; 1992)^{7}$. Ou seja, pelo uso da energia solar somado à taxa fotossintética, ocorrem todos os ecosserviços e fluxos energéticos dos sistemas naturais, como se pode observar na Tabela 3 (DE GROOT,1992).

Tabela 3 - Relação dos grupos e funções ambientais segundo De Groot et al. (1992).

\begin{tabular}{cc}
\hline $\begin{array}{c}\text { Grupos de funções } \\
\text { ambientais }\end{array}$ & Funções ambientais percebidas na área de estudo \\
\hline Funções de regulação & $\begin{array}{c}\text { Regulação do clima, regulação de distúrbios, regulação da água, } \\
\text { abastecimento de água, controle de erosão, formação do solo, ciclo de } \\
\text { nutrientes, tratamento de resíduos, polinização, controle biológico, refúgio } \\
\text { Recreação }\end{array}$ \\
Funções de Provisão & $\begin{array}{c}\text { Regulação de gás, Produção de comida, matéria-prima, recursos genéticos, } \\
\text { Funções de Produção } \\
\text { Funções de Informação }\end{array}$ \\
\hline
\end{tabular}

Costanza (1994) observa que o valor monetário que esses recursos naturais podem vir a ter está condiciona-se de maneira direta ao valor anual dos ecosserviços diminuídos por uma possível taxa de desconto, pois é por meio dessa equação (serviços ecológicos divididos pela taxa de desconto) que se calcula o valor econômico de um ecossistema. Essa abordagem não é nova e foi utilizada por diferentes autores em diversos trabalhos (COSTANZA et al., 1997; BALMFORD et al., 2002).

Resumidamente, essa técnica busca obter o valor aproximado dos ecosserviços de uma área, realizando-se a extrapolação inversa (de nível global ao nível local) dos resultados da pesquisa internacional (COSTANZA et. al 1997) para todos os serviços ambientais de uma região a ser estudada, sendo possível verificar e obter o valor monetário desta área. Um exemplo disso é o cálculo do valor ambiental da área da Cachoeira da Serrinha, em Mariana (MG) por Camargo et al. (2014).

e- Disposição a aceitar pela perda de funções ambientais

\footnotetext{
${ }^{7}$ De Groot merece um destaque especial por ter sido o primeiro a propor a divisão das funções ambientais em quatro categorias: a) regulação; b) habitat; c) produção; e d) informação; algo que seria melhor aproveitado e estudado depois por outros autores, especialmente Costanza, em 1994.
}

Página 82 Caderno de Ciências Sociais Aplicadas, Vitória da Conquista/BA, vol. 15, n 26, ano 15, p. 69-89, jul/dez 2018. 
Conhecida também como preço-sombra, essa metodologia serve para verificar a disposição a aceitar ou mesmo uma compensação financeira a receber pela perda de um bem ambiental antes presente em um local (DE GROOT, 1992).

O valor monetário que se aceita receber ao se verificar, por exemplo, a presença de um poluente na água nascente em um terreno (algo que não possui um preço dentro do mercado financeiro) pode ser feito a partir de uma compensação financeira que objetive o aceite do dano ambiental por parte do proprietário ou da população do entorno (TAFURI, 2008).

f- Método de Avaliação Contingencial (MAC)

Entre os métodos mais utilizados para analisar a disposição dos indivíduos em valorar o uso dos recursos naturais, está o Método de Avaliação Contingencial (MAC), sobre o qual Maia et al. (2004, p. 17) dissertam:

O MAC faz uso de consultas estatísticas à população para captar diretamente os valores individuais de uso e não uso atribuídos a um recurso natural. Simula um mercado hipotético, informando devidamente o entrevistado sobre os atributos do recurso a ser avaliado e interrogando o mesmo sobre sua disposição a pagar (DAP) para prevenir, ou a disposição a receber (DAR) para aceitar uma alteração em sua provisão. A DAP (ou DAR) é uma maneira de revelar as preferências das pessoas em valores monetários, e a estimativa dos benefícios totais gerados pelo recurso ambiental será dada pela agregação das preferências individuais da população.

A utilização do MAC foi sendo reconhecida à medida que novos estudos aprimoraram a técnica e forneceram base para validação dos resultados. Hoje em dia ele é aceito por diversos organismos nacionais e internacionais e utilizado para avaliação de projetos de grandes impactos ambientais.

É o único método capaz de captar valores de não uso de bens e serviços ambientais. É flexível e adaptável à quase todos os casos de valoração ambiental.

Baseado na Economia Ambiental, esse método de valoração parte do princípio da racionalidade econômica (GEORGESCU-ROEGEN, 1971), ou seja, prevalece a maximização do bem-estar de acordo com as restrições orçamentárias, sendo uma metodologia que visa mensurar um valor econômico ambiental com base na própria disposição da população em pagar pelo seu uso.

Desse modo, seu objetivo não é justapor ao bem ambiental um preço de mercado, a intenção é mensurar as preferências dos indivíduos sobre as alterações no meio ambiente local (BOCATO JR, 2009). Sua aplicação ocorre por meio da aplicação de questionários entre a população, que é estimulada a definir diretamente os valores individuais atribuídos a um recurso natural.

Página 83 Caderno de Ciências Sociais Aplicadas, Vitória da Conquista/BA, vol. 15, n 26, ano 15, p. 69-89, jul/dez 2018. 
Nesse sentido, simula-se um mercado hipotético, sem necessariamente ter conhecimento prévio do assunto (ORTIZ, 2003), apenas informando ao entrevistado as características e propriedades do recurso ambiental que está sendo avaliado e questionando a real disposição a pagar por sua preservação.

Após a definição da área onde se situa o bem ou serviço a ser valorado, é importante que seja feita uma análise qualitativa identificando as características socioeconômicas da população a ser estudada. Feito isso, inicia-se o processo de Avaliação Contingencial mediante a construção e a aplicação de um questionário semiestruturado a essa população.

Esse rol de perguntas deve conter informações básicas, como idade, gênero, nível de escolaridade e renda. O ponto principal a ser abordado, refere-se à suposição de um mercado incerto, com base no qual se analisa a disposição dos indivíduos a pagarem (ou não) pela manutenção desse bem ou serviço ambiental. Ou seja, busca-se mensurar a valoração pessoal de bens considerados, até então, incomensuráveis.

Oliveira Júnior (2003) também utiliza o método de valoração ambiental com o procedimento metodológico citado anteriormente, porém, sem a aplicação da disposição a pagar (DAP). Esse autor procurou revelar o valor dos benefícios oriundos do uso direto dos recursos naturais de sua área em estudo e recomendou o uso dessa metodologia como "ferramenta adicional para justificar a preservação ambiental" (OLIVEIRA JÚNIOR, 2003, p. 253).

A posteriori, é possível estabelecer a relação custo x benefício da aplicação do valor de uso do qual a comunidade em questão foi submetida. Pode-se, inclusive, com esse procedimento, verificar se os benefícios oriundos podem gerar, de fato, melhorias econômicas para os moradores de uma determinada região/área afetada ou se os benefícios, na verdade, se restringem a alguns.

De maneira geral, observa-se que, ao tentar transformar o meio ambiente e os recursos naturais em um bem público/recurso finito, mediante a sua valoração, é necessário que se faça todo o levantamento econômico da população da área de estudo, assim como de seus aspectos socioeconômicos locais. O cálculo, para análise da disposição que as pessoas teriam a pagar pela preservação dos recursos e serviços naturais, depende dos aspectos econômicos e sua consequente interferência no bem-estar.

Portanto, a aplicação do MAC não se restringe ao levantamento da disposição a pagar (DAP) e da disposição a receber (DAR), mas envolve todo o processo de análise social e econômica. Mesmo quando a intenção é apenas o cálculo do valor do uso direto dos bens e serviços naturais, ainda assim,

Página 84 Caderno de Ciências Sociais Aplicadas, Vitória da Conquista/BA, vol. 15, nº 26, ano 15, p. 69-89, jul/dez 2018. 
envolverá uma análise qualitativa, tanto da amostra selecionada, quanto de toda a área na qual está o objeto a ser estudado.

Outro argumento que referenda esse método, está no fato de o MAC ser cada vez mais utilizado como fundamento para punições judiciais relacionados a desastres de cunho ambiental ou mesmo ecológicos, valorando, portanto, o custo necessário para recuperação do bem natural ou até mesmo do ecossistema como um todo (MOTA, 2000).

Cabe ainda destacar que, por essa técnica, para simular um mercado hipotético-dedutivo (como já descrito anteriormente) próximo ao real, é preciso que se atente à aplicação correta da metodologia, pois, quanto menos específica ela se apresentar, maior tenderá a ser o entendimento por parte do entrevistado de que a valoração é algo meramente simbólico (BELLUZZO JR., 1995). Portanto, informações detalhadas durante a conversação são fundamentais para se chegar ao objetivo final: definição do preço a se pagar por um bem ambiental relativo a uma determinada parcela da população (BOCATO JR, 2009).

São exemplos dessa técnica os trabalhos de Oliveira Júnior (2003) sobre o potencial turístico de Brotas (SP) ou Tafuri (2008) e Camargo et al. (2017) calculando o Valor Ambiental (VA) em Parques Estaduais de Minas Gerais.

\section{Considerações finais}

Estudos teóricos capazes de explicar, mesmo que de forma resumida, o surgimento histórico das correntes teóricas que dialogam com o meio ambiente dentro das Ciências Econômicas sempre são importantes, ainda mais no momento presente em que a temática ambiental se apresenta nas manchetes de jornais e revistas.

Mostrar que as Economias Ambientais e Ecológicas não são sinônimas, apesar do ancestral comum (Economia do Meio Ambiente) também é algo a ser destacado, afinal de contas, essa é ainda uma área pouco explorada da Economia.

Outro importante ponto, sem dúvida, é mostrar de maneira simplificada que as principais técnicas de valoração dos serviços ambientais não são todas iguais como muitos imaginam, sendo, portanto, fundamental compreender não apenas as suas diferenças, mas como, quando e por que usar cada uma.

Página 85 Caderno de Ciências Sociais Aplicadas, Vitória da Conquista/BA, vol. 15, n² 26, ano 15, p. 69-89, jul/dez 2018. 


\section{Conclusões}

Infelizmente, ainda é bastante comum, profissionais de meio ambiente, das mais diversas formações, não terem a mínima noção das relações econômicas presentes na natureza. Superar esse hiato é um desafio dos mais intensos, ainda mais pensando na importância da temática no contexto atual.

Somem-se a isso, os métodos e técnicas de valoração ambiental, algo ainda recente em empreendimentos ambientais, mas que apresentam visíveis vantagens quando comparada a outras metodologias, especialmente pelo fato de serem relativamente baratas e capazes de produzir resultados aceitáveis.

Popularizar seu uso como técnica científica confiável e rentável para a preservação e mensuração monetária dos bens naturais parece ser uma importante saída para a conservação ambiental.

\section{Agradecimentos}

Os autores agradecem a Coordenação de Aperfeiçoamento de Pessoal (CAPES) pela bolsa de pesquisa do aluno.

\section{Referências}

BALMFORD, A.; BRUNER, A.; COOPER, P.; COSTANZA, R.; FARBER, S.; GREEN, R. E. et al. Economic reasons for conserving wild nature. Science, v. 297, n. 5583, p. 950-953, 2002.

BARCELOS, T. S. Valoração Econômica do Santuário do Caraça em Minas Gerais/BR. 2014. 136f. Dissertação (Mestrado em Sustentabilidade Socioeconômica e Ambiental) - Departamento de Engenharia Ambiental, Universidade Federal de Ouro Preto, Ouro Preto, 2014.

BELLIA, V. Introdução à Economia do Meio Ambiente. Ministério do Meio Ambiente, dos Recursos Hídricos e da Amazônia Legal. Brasília: Instituto Brasileiro do Meio Ambiente e dos Recursos Naturais Renováveis - IBAMA, 1996. 262p.

BELLUZZO JUNIOR., W. Valoração de bens públicos: o método de avaliação contingente. 151f. 1995. Dissertação (Mestrado em Economia) - Faculdade de Economia, Administração e Contabilidade, Universidade de São Paulo, São Paulo, 1995.

Página 86 Caderno de Ciências Sociais Aplicadas, Vitória da Conquista/BA, vol. 15, nº 26, ano 15, p. 69-89, jul/dez 2018. 
BOCATO JR, F. C. A valoração de ativos naturais urbanos: o caso da APA da Fazendinha, Amapá, Brasil. 2009. 83f. Dissertação (Mestrado em Biodiversidade Tropical) - Universidade Federal do Amapá, Macapá, 2009.

CAMARGO, P. L. T.; BARCELOS, T. S.; RIGUEIRA, C. V. L.; CARVALHO, M. M.; DIAS, J. E. C. Valoração Ambiental da Cachoeira da Serrinha, Mariana/MG Segundo o Método de Costanza (1997). Ciência e Natura, n.36, p.137-152, 2014.

CAMARGO, P. L. T.; LAMIM- GUEDES, V. ; OLIVEIRA JUNIOR, A. F. ; TEIXEIRA, M. B. ; MARTINS JUNIOR, P. P. . Uso da metodologia de valoração contigente para o cálculo do valor ambiental do vetor norte do Parque Estadual do Itacolomy (Mariana - MG). Revista Ibero-americana de Ciências Ambientais, v. 8, n.3, p. 26-39, 2017.

CAVALCANTI, C. Desenvolvimento e natureza: estudo para uma sociedade sustentável. São Paulo: Cortez, 1995. 429p.

COMISSÃO MUNDIAL SOBRE MEIO AMBIENTE E DESENVOLVIMENTO. Nosso Futuro Comum. Rio de Janeiro: Fundação Getúlio Vargas, 1988.

COSTANZA, R. Economia Ecológica: uma agenda de pesquisa. In: MAY, P. H.; MOTA, R. S. da (Orgs.). Valorando a Natureza: Analise Econômica para o Desenvolvimento Sustentável. Rio de Janeiro: Campus, 1994. p.111-144.

COSTANZA, R.; D’ARGE, R.; DE GROOT, R. S.; FARBER, S.; GRASSO, M.; HANNON, B.; LIMBURG, K.; NAEEM, S.; O’NEILL, R.V.; PARUELO, J.; RASKIN, R. G.; SUTTON, P.; VAN DEN BELT, M. The value of the world's ecosystem services and natural capital. Nature, v. 387, p. 253-260, 1997.

COSTANZA, R.; D’ARGE, R.; DE GROOT FARBER, S.; GRASSO, M.; HANNON, B.; LIMBURG, K.; NAEEM, S.; O’NEILL, R. V.; PARUELO, J.; RASKIN, R. G.; SUTTON, P.; VAN DEN BELT, M. The value of ecosystem services: putting the issues in perspective. Ecological Economics, v. 25, p. 67-72, 1998.

CROPPER, M. L.; OATES W. E. Environmental Economics: A Survey. Journal of Economic Literature, v.30, n.2, p. 675-740, 1992.

CARSON, R. L. Primavera Silenciosa. São Paulo: Gaia, 2010. 327p.

DENARDIN, V. F. Abordagens econômicas sobre o meio ambiente e suas implicações quanto aos usos dos recursos naturais. Revista Teoria e Vivência Econômica, v. 11, n. 21, p 129-149, 2003.

DE GROOT, R. S. Environmental functions as a unifying concept for ecology and economics. Environmentalist, v. 7, n. 2, p. 105-109, 1987.

DE GROOT, R. S. Functions of Nature: Evaluation of nature in environmental planning, management and decision making. Amsterdam: Wolters-Noordhoff, 1992.

Página 87 Caderno de Ciências Sociais Aplicadas, Vitória da Conquista/BA, vol. 15, nº 26, ano 15, p. 69-89, jul/dez 2018. 
GEORGESCU-ROEGEN, N. The Entropy Law and the Economic Process. Cambridge : Harvard University Press, 1971. 457p

GONÇALVES-DIAS, S. L. F.; TEODOSIO, A. S. S.; BARBIERI, J. C. Desafios e perspectivas da sustentabilidade: caminhos e descaminhos na gestão empresarial. In: ENCONTRO DE GESTÃO EMPRESARIAL E MEIO AMBIENTAL, 9., 2007, Curitiba. Anais...Curitiba: ENGEMA, 2007. p.112

MAIA, A. G.; ROMEIRO, A. R.; REYDON, B. P. Valoração de Recursos Ambientais: metodologias e recomendações. IE/UNICAMP, n. 116, 2004. (Texto para Discussão)

MATTOS, K.; MATTOS, K. M.; MAT'TOS, A. Valoração econômica do meio ambiente dentro do contexto do desenvolvimento sustentável. In: SIMPÓSIO DE ENGENHARIA DA PRODUÇÃO, 11., 2004, Bauru. Anais... Bauru: SIMPEP, 2004.

MCCORMICK, J. As raízes do ambientalismo. In: MCCORMICK, J. Rumo ao paraíso: a história do movimento ambientalista. Rio de Janeiro: Relume-Dumará, 1992. p. 21-41.

MERICO, L. F. K. Introdução à economia ecológica. Blumenau: FURB, 1996. 160p.

MOTA, J. A. Valoração de ativos ambientais como subsídio à decisão pública. 2000. 262f. Tese (Doutorado em Desenvolvimento Sustentável, área de concentração Política e Gestão Ambiental) Universidade de Brasília, Centro de Desenvolvimento Sustentável, Brasília, 2000.

MOTTA, R. S. Manual para valoração econômica de recursos ambientais. Rio de Janeiro: IPEA/MMA/PNUD/CNPq,1997.

MUELLER, C. C. Avaliação de duas correntes da economia ambiental: a escola neoclássica e a economia da sobrevivência. Revista de Economia Política, v.18, n. 2, p.66 - 89, 1998.

NETO, G. K. Valoração Ambiental dos Recursos Naturais. Disponível em: >http://www.geokas.blogspot.com.br/2010/09/valoracao-ambiental.html.>. Acesso em: 10 dez. 2012.

NOGUEIRA, J. M.; MEDEIROS, M. A. A. As interfaces entre políticas setoriais e a política de meio ambiente: aspectos conceituais e operativos básicos de política pública. Brasília: UnB/NEPAMA, 1999. 30 p.

OBARA, A. T. Valoração Econômica de Unidades de Conservação - método de valoração de contingente - caso de estudo: Estação Ecológica de Jataí, Luiz Antonio, SP. 1999. 111p. Tese (Doutorado em Ecologia e Recursos Naturais) - Centro de Ciências Biológicas e da Saúde, Universidade Federal de São Carlos, São Carlos, 1999.

OLIVEIRA JUNIOR, A. F. Valoração econômica da função ambiental de suporte relacionada às atividades de turismo, Brotas, SP. 277f. 2003. Tese (Doutorado Ecologia e Recursos Naturais) Centro de Ciências Biológicas e da Saúde, Universidade Federal São Carlos, São Carlos, 2003.

Página 88 Caderno de Ciências Sociais Aplicadas, Vitória da Conquista/BA, vol. 15, nº 26, ano 15, p. 69-89, jul/dez 2018. 


\section{- Cadernos de CIIENCIAS SOCIAIS APLICADAS}

ONU. Organização das Nações Unidas. Conferência das Nações Unidas Sobre Desenvolvimento Sustentável. Disponível em: <http://www.onu.org.br/rio20/img/2012/01/rio92>. Acesso em: fev. 2012.

ORTIZ, R. A. Valoração Econômica Ambiental. In: MAY, Peter H. et al. (orgs). Economia do meio ambiente: teoria e prática. Rio de Janeiro: Elsevier, 2003. p.81-99

PEARCE, D.; WARFORD, J. World without end: economics, environment and sustainable development. New York: Oxford University Press, 1993.

SOARES, B. E. C.; NAVARRO, M. A.; FERREIRA, A. P. Desenvolvimento Sustentado e Consciência Ambiental: Natureza, Sociedade e Racionalidade. Ciências \& Cognição, v.2, p.42-49, 2004.

TAFURI, A. C. Valoração ambiental do Parque Estadual do Itacolomi. 159f. 2008. Dissertação (Mestrado em Saneamento, Meio Ambiente e Recursos Hídricos) - Escola de Engenharia, Universidade Federal de Minas Gerais, Belo Horizonte, 2008.

TURNER, R. K. Economics, Growth and Sustainable Environments. London: Macmillan, 1988. 